\title{
Renewable energy and population growth for sustainable development in the Southeast Asian countries
}

\author{
Duc Hong Vo* (10) and Anh The Vo
}

\begin{abstract}
The energy-environment-growth nexus has been examined for the Association of Southeast Asian Nations (ASEAN) region, mainly using time series data. However, the important role of renewable energy and population has largely been ignored in previous studies. As such, this study is conducted to investigate a causal link between renewable energy usage, population, carbon dioxide emissions, and economic growth. In addition, a relatively new and advanced panel vector autoregressive model and the Granger non-causality test for heterogeneous panels are utilized with a sample of seven ASEAN countries for almost three decades since 1990. Key findings from this paper are as follows. First, renewable energy usage responds to population growth and leads to carbon dioxide $\left(\mathrm{CO}_{2}\right)$ emissions. Second, economic growth and renewable energy usage explain a substantial proportion of the change in energy consumption. Third, a bidirectional Granger causality does exist in each pair among energy consumption, economic growth and $\mathrm{CO}_{2}$ emissions. We argue that moderating population growth and extending renewable energy usage are vital to achieving sustainable economic growth in the ASEAN region.
\end{abstract}

Keywords: Renewable energy usage, Population, $\mathrm{CO}_{2}$ emissions, Economic growth, Granger non-causality, Panel vector autoregressive (panel VAR) model

\section{Background}

A growing concern on the interaction among carbon emissions, economic growth, and energy consumption has been driven by the trade-off between economic growth and environmental degradation. The concern appears to be more prevalent and severe in the Association of Southeast Asian Nations (ASEAN) region. The region has been facing a dual challenge of maintaining economic growth and addressing environmental problems [1]. The adverse effect of greenhouse gas on environmental degradation can threaten individuals' well-being both at a country level and at a regional

*Correspondence: duc.vhong@ou.edu.vn

The CBER - Research Centre in Business, Economics \& Resources, Ho Chi Minh City Open University, 97 Vo Van Tan Street, District 3, Ho Chi Minh City, Vietnam level. The ASEAN region witnesses a notable increase in economic growth over the past decades and expects to maintain its growth rate in many years to come. Economic growth exerts increasing pressure on the demand for energy, which currently relies heavily on fossil fuels [2]. Energy demand in the ASEAN region is predicted to grow as much as 2.3 times (or 230 per cent) by 2040 . Therefore, ASEAN country members have to make great efforts to deal with environmental degradation and ensure energy security by adopting feasible targets for renewable energy [3]. For example, Indonesia, the Philippines and Thailand have developed and implemented a plan to increase the share of renewable energy in the total primary energy supply. Malaysia targets to increase the

(c) The Author(s) 2021. Open Access This article is licensed under a Creative Commons Attribution 4.0 International License, which permits use, sharing, adaptation, distribution and reproduction in any medium or format, as long as you give appropriate credit to the original author(s) and the source, provide a link to the Creative Commons licence, and indicate if changes were made. The images or other third party material in this article are included in the article's Creative Commons licence, unless indicated otherwise in a credit line to the material. If material is not included in the article's Creative Commons licence and your intended use is not permitted by statutory regulation or exceeds the permitted use, you will need to obtain permission directly from the copyright holder. To view a copy of this licence, visit http://creativecommons.org/licenses/by/4.0/. The Creative Commons Public Domain Dedication waiver (http://creativeco mmons.org/publicdomain/zero/1.0/) applies to the data made available in this article, unless otherwise stated in a credit line to the data. 
capacity of renewable electricity supply to around 8 per cent of total installed capacity.

Renewable energy releases lesser carbon dioxide $\left(\mathrm{CO}_{2}\right)$ emissions, thus mitigating the negative impact on the environment. Apart from not being depleted, renewable energy offers a wide range of merits: increased energy security, sustainable economic growth, and pollution reduction $[4,5]$. The ASEAN members have acknowledged that the use of renewable energy is associated with a reduction of reliance on fossil fuels, thus achieving targeted economic growth and energy security, affordability and sustainability. Therefore, the framework of the ASEAN Economic Community (ACE) was adopted. Countries continue improving technological innovation, reducing the costs of renewable energy and setting a target that renewable energy will account for 23 per cent of the total energy supply by 2025 [3]. Thus, renewable energy has played an increasingly important role in supporting economic growth and reducing a negative impact on the environment in the region. The region has now been facing the increased pressure from population growth among the members. As such, the main focus of this paper is to examine the causal link between population, renewable energy, economic growth, $\mathrm{CO}_{2}$ emissions and energy consumption. The sample of seven ASEAN members, the ASEAN-7, is used in this study.

Our paper differs from other previous studies in two aspects. First, we focus on a sample of the ASEAN countries using the panel data. Second, the empirical results from our study provide new insights into a traditional relationship between energy consumption and economic growth. In this paper, renewable energy usage, which has recently attracted attention and debate among scholars, is carefully examined. Our research framework extends the work [6] by investigating the causal link between $\mathrm{CO}_{2}$ emissions, economic growth, population growth, and renewable energy in a larger panel of countries across the region. Various tests, including a slope homogeneity test, a unit root test, and the cointegration test, are used to address cross-sessional dependence and slope homogeneity among countries.

This paper focuses on the ASEAN-7 and the short-run relationship. Our paper contributes to the current literature and offers policy implications for the ASEAN countries and other emerging markets. Empirical findings from previous studies confirm the importance of renewable energy in boosting economic growth, reducing $\mathrm{CO}_{2}$ emissions and supplementing an increasingly substantial demand for energy consumption. However, little attention has been paid to the ASEAN region, with exceptions [7-9]. Understanding the causal relationship among population, renewable energy usage, and economic growth is important for policymakers to adopt and implement renewable energy and energy-intensive policies.

Second, a recently developed panel vector autoregressive (VAR) model is used in this paper. Unlike other empirical studies in the ASEAN region confirming the long-run relationship, we are interested in the short-run relationship among renewable energy usage, energy consumption, economic growth, population, and $\mathrm{CO}_{2}$ emissions. Our paper is the first of its kind that employs an advanced econometrics approach for a sample of seven ASEAN countries. The panel VAR model is used together with the system generalized method of moments (GMM) estimator rather than the ordinary least square method. The GMM method generates a more efficient and robust estimator [10-12]. In addition, the panel VAR framework can deal with the potential issue of endogeneity. The approach treats all the concerned variables as endogenous, places them in a system of equations, and controls the country's fixed effects and lagged interdependence. Finally, the panel VAR model has been increasingly attractive among scholars in the energy economic literature [13-15].

The paper is organized as follows. Following this introduction, Sect. 2 discusses relevant theories and empirical studies. The research methodology and data descriptions are presented and discussed in Sect. 3. Section 4 presents empirical results, followed by the discussions on the empirical findings in session 5. Finally, our concluding remarks and policy implications are discussed in Sect. 6 of the paper.

\section{Literature review}

The topic of causal links between $\mathrm{CO}_{2}$ emissions, economic growth, and energy consumption has been widely discussed in energy economics. Various directional causalities have been extensively investigated in the developed countries. For example, the time-varying causalities between $\mathrm{CO}_{2}$ emissions, energy consumption, and economic growth of 50 American states from 1960 to 2010 using a time-varying VAR approach are confirmed [16]. Furthermore, selected studies have used panel econometrics techniques to examine the link between $\mathrm{CO}_{2}$ emissions and economic growth, energy consumption in the ASEAN region. Based on the panel quantile regression, an analysis examines foreign direct investment, economic growth, and energy consumption on $\mathrm{CO}_{2}$ emissions for ASEAN-5 countries, namely, Indonesia, Malaysia, the Philippines, Singapore and Thailand for 1981-2011 [17]. In addition, the ASEAN-5 sample for 1970-2016 is employed in the study [1] to investigate the causal relationship between $\mathrm{CO}_{2}$ emissions, economic growth, and energy consumption. That study takes the cross-sectional dependence into account for the panel analysis. 
Meanwhile, that paper utilizes the panel smooth transition regression model and the panel quantile regression [18]. In these panel-based studies, we note that the role of renewable energy and population growth to economic growth and environmental degradation has largely been ignored.

The empirical studies that incorporate renewable energy in energy consumption-economic growth-environmental quality nexus in the ASEAN region are limited. The impact of renewable and non-renewable energy consumption on economic growth is documented in a panel of five ASEAN countries [8], where there exists a positive effect of energy consumption on economic growth, both renewable and non-renewable. Another empirical study examines the effect of per capita renewable energy consumption on $\mathrm{CO}_{2}$ emissions for ASEAN-4 countries, namely, Indonesia, Malaysia, the Philippines, and Thailand, using the time-series data analysis [9]. Their findings indicate that an increase in renewable energy consumption is associated with reducing $\mathrm{CO}_{2}$ emissions. That paper supports the view that renewable energy usage appears to be a solution to reduce environmental degradation. Nathaniel and Khan [7] consider the impact of renewable and non-renewable energy consumption on environmental degradation for a panel of ASEAN countries. Economic growth, urbanization and trade are used as controlled variables. That study uses an ecological footprint as a proxy for environmental degradation. Findings from the paper indicate that economic growth and non-renewable energy consumption are the primary sources of environmental degradation in the long run. However, renewable energy consumption does not affect environmental degradation in the long run, not only for the whole panel of ASEAN countries but also for the individual country in the sample.

The causal relationship between $\mathrm{CO}_{2}$ emissions and energy consumption has been found in the energy literature extensively and empirically. Hwang and Yoo [19] reveal a bidirectional causality between $\mathrm{CO}_{2}$ emissions and energy consumption in Indonesia. Saboori and Sulaiman [20] employ a vector error correction model to investigate the causal link between $\mathrm{CO}_{2}$ emissions and energy consumption for the ASEAN-5 countries over 1971-2009. Long-run causality from energy consumption to $\mathrm{CO}_{2}$ emissions is found in Malaysia, the Philippines, Singapore and Thailand, while short-run causality is observed in Indonesia, Malaysia, the Philippines and Singapore. Moreover, findings from the study found that estimated elasticities, in the long run, are larger than in the short run. These findings also imply that the effect of energy consumption on $\mathrm{CO}_{2}$ emissions increases over time in these five ASEAN countries. An inverted U-shaped relationship between energy consumption and
$\mathrm{CO}_{2}$ emissions exists in Pakistan from 1971 to 2011, using an autoregressive distributed lagged (ARDL) bounds test framework (2017). The effect of energy consumption on $\mathrm{CO}_{2}$ emissions is positive when the energy consumption is below a certain threshold. However, the effect becomes negative when energy usage passes a threshold. An analysis by [22] investigates the energy-growth-environment relationship in seven emerging countries by applying a bootstrap ARDL bounds test to cointegration controlling for structural breaks. The results fail to confirm the long-run relationship between economic growth, energy consumption and $\mathrm{CO}_{2}$ emissions. However, the study confirms the short-run causality, which is different from one country to another.

The sources of energy consumption should be incorporated in the relationship between energy consumption and environmental degradation. Vietnam experiences a significantly positive relationship between fossil fuel energy consumption and $\mathrm{CO}_{2}$ emissions [23]. In contrast, Raza and Shah [24] confirm a negative relationship between $\mathrm{CO}_{2}$ emissions and renewable energy for the G7 countries (including Canada, France, Germany, Italy, Japan, the United Kingdom, and the United States). Nguyen and Kakinaka [25] affirm that the relationship between renewable energy consumption and $\mathrm{CO}_{2}$ emissions is dependent on the development stages for 107 countries from 1990 to 2013. Renewable energy consumption is positively correlated with $\mathrm{CO}_{2}$ emissions and negatively correlated with economic growth for low-income countries. However, the outcomes are reversed for high-income countries. China and India experience a negative impact of hydroelectricity on $\mathrm{CO}_{2}$ emissions during 1965-2013 [26]. Economic well-being, trade freedom and business freedom play a contributing role to renewable energy consumption in the panel data of 32 African countries [27]. Recent literature on the link between carbon emissions, economic growth, energy consumption (in general) has also been considered from both market integration and (price) convergence perspectives.

Few studies have been conducted to examine the energy-environment-growth nexus in the Asian region. Nepal and Paija [28] examine the inter-relationship between energy security, electricity consumption, population, and economic growth for Nepal, a developing resource-rich country. Using the ARDL bounds tests approach to cointegration, the authors fail to confirm the long-run relationship among these variables. However, their findings support the positive effect of population growth on electricity consumption. Another analysis conducted by these authors takes advantage of a time series approach to consider the energy-environment-growth nexus with control variables, including population and 
gross fixed capital. The empirical findings document a unidirectional Granger causality running from economic growth to energy consumption and $\mathrm{CO}_{2}$ emissions to real output [29]. A study is conducted to investigate the energy-environment-growth nexus for Malaysia [30]. The increased energy consumption and economic growth are positively associated with environmental degradation, which is not impacted by population growth.

Another stream of empirical research uses the stochastic impacts by regression on population, affluence, and technology (STIRPAT) framework on the energy-environment-growth nexus. This framework is also applied to investigate the role of demographic and economic factors on environmental degradation [31]. A key conclusion from this stream of research is that economic growth rather than population growth increases $\mathrm{CO}_{2}$ emissions. A noteworthy feature of their work is to use extensive panel data of 84 countries and 25 years and the traditional and standardized STIRPAT frameworks. An extended version that combines the STIRPAT framework and the dynamic common correlated effects estimators is used to investigate a wide range of factors contributing to $\mathrm{CO}_{2}$ emissions for ten newly industrialized countries [32]. These factors include real output, energy intensity, energy mix, labour productivity, urban employment, trade openness, and population. The study concludes that the first four factors are the primary sources of $\mathrm{CO}_{2}$ emissions. The next two factors are marginal contributors. The population growth has no effect. Previous empirical findings confirm the significant effect of key factors on $\mathrm{CO}_{2}$ emissions. Furthermore, the effect varies across the surveyed countries and studies.

\section{Model and methodology \\ Model specification}

Our main objective is to analyze the causal link between renewable energy usage, population growth, carbon emissions, energy consumption and economic growth. The choice of these variables is based on the STIRPAT model, developed by Dietz and Rosa [33] and recently applied by [30,34]. Population growth and economic activity are two main elements of $\mathrm{CO}_{2}$ emissions. The energy-economic literature has been intensively investigated on the link between economic growth, energy consumption and environmental quality (see [35] for a review). Given the increasingly important role of renewable energy usage in contemporary energy literature [36-38], we add the variable of renewable energy in our analysis. The model specification is expressed as follows:

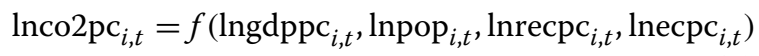

Table 1 Data description

\begin{tabular}{lcrrrr}
\hline Variable & Obs. & \multicolumn{1}{c}{ Mean } & Std. Dev. & \multicolumn{1}{c}{ Min } & \multicolumn{1}{c}{ Max } \\
\hline co2pc & 174 & 3.42 & 3.93 & 0.10 & 18.04 \\
gdppc & 174 & $7,661.63$ & $12,407.16$ & 193.24 & $52,244.44$ \\
pop & 174 & 74.01 & 65.56 & 3.05 & 255.13 \\
recpc & 174 & 200.75 & 102.05 & 7.37 & 474.60 \\
есрс & 174 & $1,519.44$ & $1,653.52$ & 254.45 & $7,370.65$ \\
\hline
\end{tabular}

co2pc per capita $\mathrm{CO}_{2}$ emissions, $g d p p c$ per capita real GDP, pop population, recpc per capita renewable energy consumption, ecpc per capita energy consumption

where $i$ and $t$ represent the number of countries and the time period, respectively. $\mathrm{co}_{2} \mathrm{pc}_{i t}$ is the amount of $\mathrm{CO}_{2}$ emissions, and $\mathrm{gdppc}_{i, t}$ is the real per capita gross domestic product (GDP). recpc $c_{i, t}$ is the amount of renewable energy usage. ecpc $i, t$ is energy consumption. pop ${ }_{i, t}$ is the population of each country $i$ over the period $t$. Finally, $\varepsilon_{i t}$ is the error term, and "ln" denotes the nature of the logarithm.

Data are collected from the World Bank Indicators database, including $\mathrm{CO}_{2}$ emissions (metric tons per capita), and real per capita GDP (GDP measured in constant 2010 US\$), renewable energy usage (percentage of total final energy consumption multiplied by the total final energy consumption per capita), energy consumption (kilogram of oil equivalent per capita), population size (total population in a million number). Seven ASEAN members, the ASEAN-7, namely, Indonesia, Malaysia, Myanmar, the Philippines, Singapore, Thailand and Vietnam, are included in the sample over the 1990-2014 period, except for Vietnam, which the timeframe ended in 2013. As such, we obtain an unbalanced panel of 174 observations, which consist of seven cross-sectional countries and 25 years. Table 1 shows descriptive statistics for the variables in this study.

\section{Methodology}

The panel VAR model is employed for the causality analysis as it provides sufficient information about the relationship among the variables of interest. The panel VAR technique has been employed to analyze dynamic effects among variables in various research areas [15]. The panel VAR framework treats all variables as endogenous and controls the heterogeneity in the panel $[12,39]$. The panel VAR framework can be expressed as follows:

$$
Y_{i, t}=A_{0}+\sum_{s=1}^{m} A_{s} Y_{i, t-s}+c_{i}+d_{c, t}+\varepsilon_{i, t}
$$

where $i$ represents the number of cross-sectional countries and $s$ is the lagged length, determined by the serial correlation test of the dependent variable. All the 


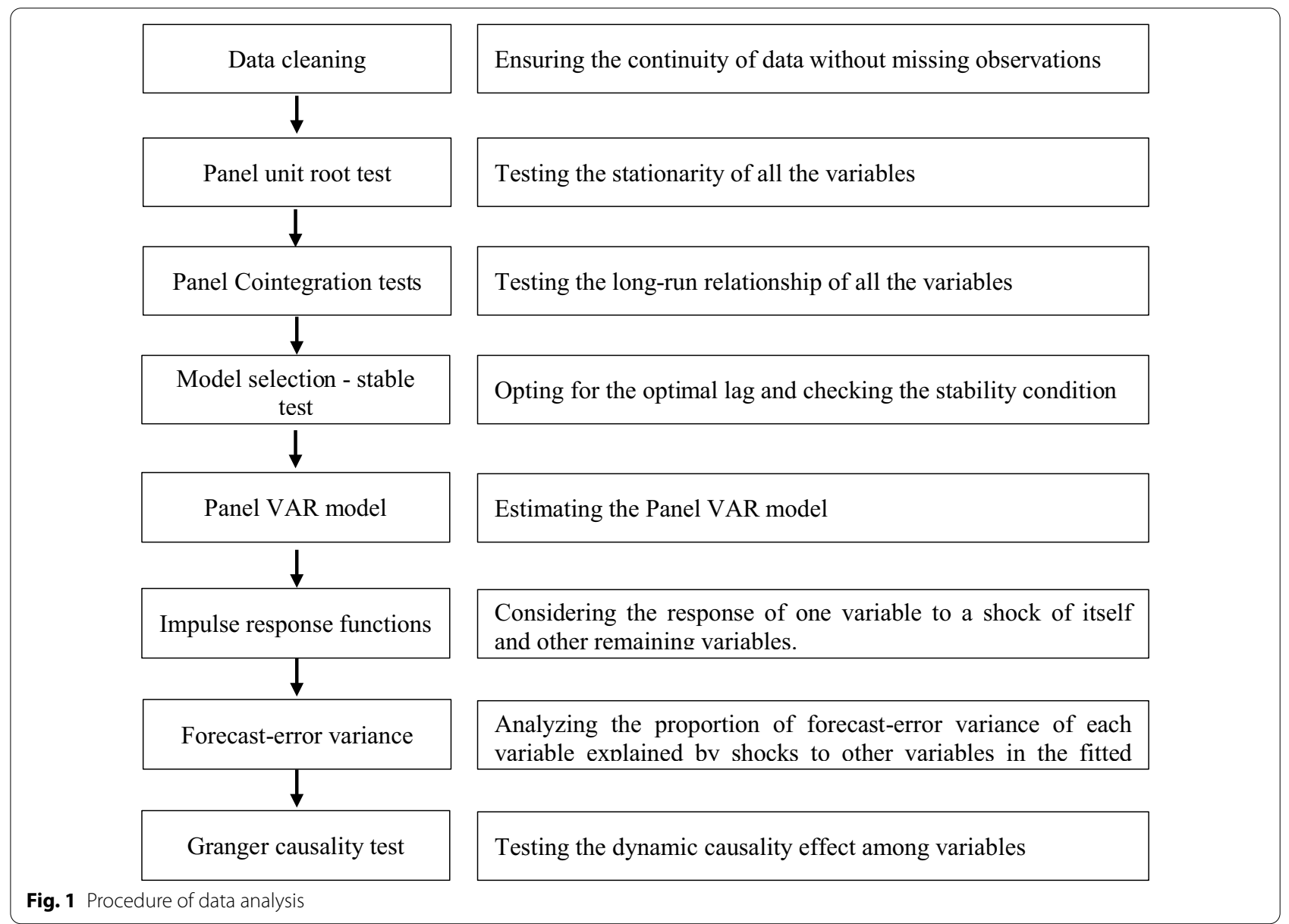

countries $i$ at time $t$ are assumed to have the same structure in the model. Like previous studies [12, 14, 15, 39], we employ the panel VAR on the ground of the generalized method of moments (GMM) estimators [40].

In this framework, $Y_{i, t}$ consists of five variables of interest, expressed a $(1 \times k)$ vector of endogenous variables:

$$
Y_{i, t}=(\mathrm{dlnco} 2 \mathrm{pc}, \mathrm{dlngdppc}, \mathrm{dln} p o p, \text { dlnrecpc, dlnecpc })
$$

$A_{s}$ is the coefficient vector to be estimated. $\varepsilon_{i, t}$ denotes idiosyncratic errors that are assumed to be identically and normally distributed, with $E\left(\varepsilon_{i, t}\right)=0$, $E\left(\varepsilon_{i, t}^{\prime} \varepsilon_{i, t}\right)=\sum$, and $E\left(\varepsilon_{i, t}^{\prime} \varepsilon_{i, s}\right)=0$ for $t>s . d_{c, t}$ is a country-specific time dummy to control the year effects, and $c_{i}$ is to consider the fixed effects of the country in Eq. (2).

The whole data analysis process, which includes eight major steps, is depicted in the flowchart in Fig. 1.

\section{Results}

We use the panel unit root test by Choi [41] to examine the stationarity of the variables. This panel-based test is a modified version from a standard Dickey-Fuller unit root test [42]. Table 2 presents the results of the unit root tests. These tests include four types of statistics: inverse chi-square, inverse normal, inverse logit, and modified inverse chi-square. All these statistics reject the null hypothesis of containing the unit root at the first difference rather than at the level, indicating all variables are integrated $I(1)$.

Two widely used cointegration tests for panel data are employed to examine the existence of a long-run relationship. Pedroni $[43,44]$ develop critical inference and asymptotic properties for the residual-based test in dynamic panels. Westerlund [45] construct the errorcorrection-based cointegration tests for panel data. ${ }^{1}$ Table 3 presents the results of these panel cointegration

\footnotetext{
${ }^{1}$ The panel cointegration tests by Pedroni and Westerlund are performed by the command xtpedroni and xtwest in Stata 15, respectively.
} 
Table 2 Results of the unit-root tests

\begin{tabular}{|c|c|c|c|c|}
\hline & Inverse chi-squared & Inverse normal & Inverse logit $t$ & $\begin{array}{l}\text { Modified } \\
\text { inverse chi- } \\
\text { squared }\end{array}$ \\
\hline & $P$ & $z$ & $L^{*}$ & $\mathrm{Pm}$ \\
\hline \multicolumn{5}{|l|}{ Thelevel } \\
\hline Inco2pc & 10.46 & 0.28 & 0.31 & -0.70 \\
\hline Ingdppc & 3.99 & 3.23 & 3.44 & -1.89 \\
\hline Inpop & 3.67 & 1.91 & 1.83 & -1.95 \\
\hline Inrecpc & 16.56 & 0.19 & 0.39 & 0.48 \\
\hline Inecpc & $21.23^{*}$ & -0.78 & -0.83 & $1.36^{*}$ \\
\hline \multicolumn{5}{|c|}{ The first difference } \\
\hline dlnco2pc & $25.42^{* *}$ & $-2.41^{* * *}$ & $-2.30^{* *}$ & $2.16^{* *}$ \\
\hline dlngdppc & $25.39^{* *}$ & $-2.23^{* *}$ & $-2.19^{* *}$ & $2.15^{* *}$ \\
\hline dlnpop & $70.30^{* * *}$ & $-1.56^{*}$ & $-5.31^{* * *}$ & $10.64^{* * *}$ \\
\hline dlnrecpc & $42.91^{* * *}$ & $-4.05^{* * *}$ & $-4.31^{* * *}$ & $5.46^{* * *}$ \\
\hline dlnecpc & $32.37^{* * *}$ & $-2.83^{* * *}$ & $-2.92^{* * *}$ & $3.47^{* * *}$ \\
\hline
\end{tabular}

"In" and " $d$ " represent the variables in terms of the logarithm and the first difference

***Denotes the rejection of containing unit roots at a significance level of $1 \%$. The test includes an intercept. One lag is included for Inpop, and three lags for other remaining variables

Table 3 Results of cointegration tests

The error-correction-based cointegration tests by Westerlund [45]

\begin{tabular}{lrrrr}
\hline & Gt & Ga & Pt & Pa \\
\hline Statistics & -2.72 & -0.29 & -14.11 & -0.27 \\
$Z$-value & -0.76 & 4.38 & -7.78 & 3.15 \\
P-value & 0.22 & 1.00 & 0.00 & 1.00
\end{tabular}

The residual-based cointegration test by Pedroni $[43,44]$

\begin{tabular}{lllll}
\hline & $\boldsymbol{v}$ & rho & $\boldsymbol{t}$ & ADF \\
\hline Panel statistics & -0.66 & 0.09 & -1.99 & -1.53 \\
Group statistics & & 1.12 & -1.61 & -1.08 \\
\hline
\end{tabular}

In the error-correction-based cointegration tests, $G t$ and $G a$ are the group-mean tests, while $P t$ and $P a$ are the panel tests

Table 4 Results of the optimal lag selection

\begin{tabular}{lllllr}
\hline Lag & CD & J & J-pvalue & MBIC & MHIC \\
\hline 1 & 0.82 & 83.87 & 0.23 & $-282.34^{*}$ & $-66.13^{*}$ \\
2 & 0.95 & 63.68 & 0.09 & -180.46 & $-153.99^{*}$ \\
3 & 0.79 & 28.77 & 0.27 & -93.30 & -94.89 \\
\hline
\end{tabular}

$J$ and $J$-pvalue denote Hansen'J statistics and the corresponding $p$-value for testing over-identifying restrictions

$C D$ coefficient of determination, MBIC moment model selection criteria (MMSC)-Bayesian information criterion (BIC), MAIC MMSC-Akaike information criterion (AIC), MHQIC MMSC-Hannan and Quinn information criterion (HQIC)

tests. Again, we find no long-run relationship among the selected variables, because both tests fail to reject the null hypothesis of no cointegration.

As all variables are $I(1)$ without cointegration, they are transformed into the first difference to ensure that the variables are stationary. As for the panel VAR analysis, the procedure begins with the selection of optimal lag length. In Table 4, the first-order panel VAR is the preferred model as three criteria have the smallest value. Therefore, we use one lag in the panel VAR model. The 


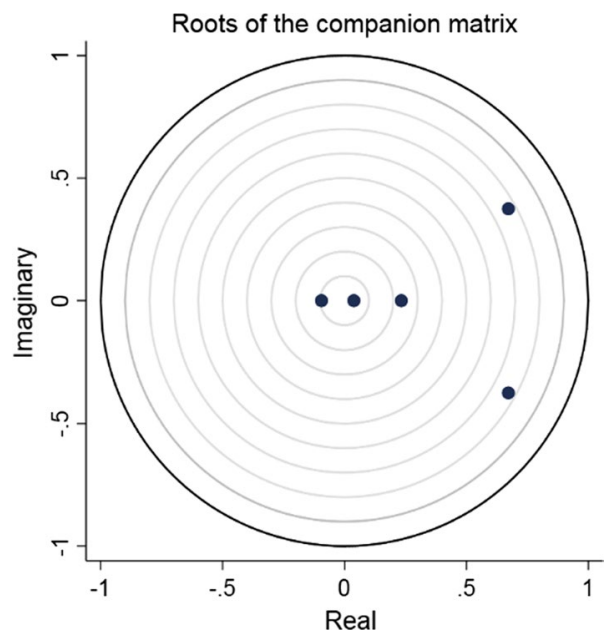

Fig. 2 Roots of the companion matrix because the roots of the companion matrix are all inside the unit circle $[10,14,15]$.

Table 5 presents the estimated results from the panel VAR analysis on the relationship between $\mathrm{CO}_{2}$ emissions, economic growth, population, renewable energy consumption, and energy consumption for the ASEAN-7. First, column (1) indicates that $\mathrm{CO}_{2}$ emissions are negatively associated with economic growth. Second, column (2) on the economic growth equation confirms a positive relationship between economic growth and environmental degradation, while economic growth is negatively found to population growth. We observe that renewable energy has no effect on economic growth in the ASEAN region. However, its impact on $\mathrm{CO}_{2}$ emissions is negative. This result supports the view that the ASEAN region has increasingly been adopting renewable energy. However, the vital role of renewable energy in promoting economic growth and supplementing energy consumption appears to be negligible, because renewable energy still accounts

Table 5 Estimated results from the panel VAR

\begin{tabular}{|c|c|c|c|c|c|}
\hline & \multicolumn{5}{|c|}{ Dependent variable } \\
\hline & $\begin{array}{l}\text { dlnco2pc } \\
\text { (1) }\end{array}$ & $\begin{array}{l}\text { Dlngdppc } \\
\text { (2) }\end{array}$ & $\begin{array}{l}\text { Dlnpop } \\
\text { (3) }\end{array}$ & $\begin{array}{l}\text { Dlnecpc } \\
\text { (4) }\end{array}$ & $\begin{array}{l}\text { DInrecpc } \\
\text { (5) }\end{array}$ \\
\hline \multicolumn{6}{|c|}{ Independent variables } \\
\hline \multirow[t]{2}{*}{ dlnco2pc(-1) } & $0.157^{* * *}$ & $0.021^{* * *}$ & $-0.014^{* * *}$ & $0.081^{* * *}$ & 0.001 \\
\hline & {$[0.048]$} & {$[0.007]$} & {$[0.001]$} & {$[0.017]$} & {$[0.012]$} \\
\hline \multirow[t]{2}{*}{ dlngdppc(-1) } & $-1.019^{* * *}$ & $0.511^{* * *}$ & $0.104^{* * *}$ & $-0.257^{* * *}$ & -0.087 \\
\hline & {$[0.190]$} & {$[0.050]$} & {$[0.011]$} & {$[0.093]$} & {$[0.117]$} \\
\hline \multirow[t]{2}{*}{ dlnpop $(-1)$} & -1.453 & $-1.721^{* * *}$ & $0.774^{* * *}$ & $-3.575^{* * *}$ & $-3.747^{* * *}$ \\
\hline & {$[1.035]$} & {$[0.258]$} & {$[0.041]$} & {$[0.585]$} & {$[0.469]$} \\
\hline \multirow[t]{2}{*}{$\operatorname{dlnecpc}(-1)$} & $0.340^{* * *}$ & $-0.068^{* * *}$ & 0.000 & 0.042 & $-0.302^{* * *}$ \\
\hline & {$[0.079]$} & {$[0.019]$} & {$[0.003]$} & {$[0.043]$} & {$[0.054]$} \\
\hline \multirow[t]{2}{*}{ dlnrecpc $(-1)$} & $-0.094^{* * *}$ & 0.005 & $-0.006^{* * *}$ & -0.035 & 0.037 \\
\hline & {$[0.035]$} & {$[0.009]$} & {$[0.002]$} & {$[0.031]$} & {$[0.037]$} \\
\hline
\end{tabular}

"In" represents the variables in terms of the logarithm

co2pc per capita $\mathrm{CO}_{2}$ emissions, gdppc per capita real GDP, pop population; recpc per capita renewable energy consumption, ecpc per capita energy consumption ***Denotes the coefficients are at the significance level of $1 \%$. The robust error terms are in square brackets

next stage is to consider the fitness and stability by calculating the moduli of the companion matrix based on the estimated parameters.

Figure 2 depicts the eigenvalue stability condition by plotting all the real and imaginary eigenvalues in the companion matrix. The stability condition is satisfied,

\footnotetext{
${ }^{2}$ All residual diagnostic tests have been conducted to ensure the appropriateness of the PVAR model. Results from these tests are not presented in this paper due to the required length of the paper. However, they will be made able upon request. We thank the reviewer for this excellent suggestion.
}

for a small proportion of the total energy consumption [46]. Third, column (3) shows that population growth is positively related to economic growth and negatively associated with $\mathrm{CO}_{2}$ emissions and renewable energy. This result is consistent with the STIRPAT model, which implies population growth as an essential determinant of economic activity and environmental degradation. Fourth, in the energy consumption equation, the results show that environmental degradation positively causes energy consumption. Fifth, renewable energy consumption is negatively linked with population growth and energy consumption. 


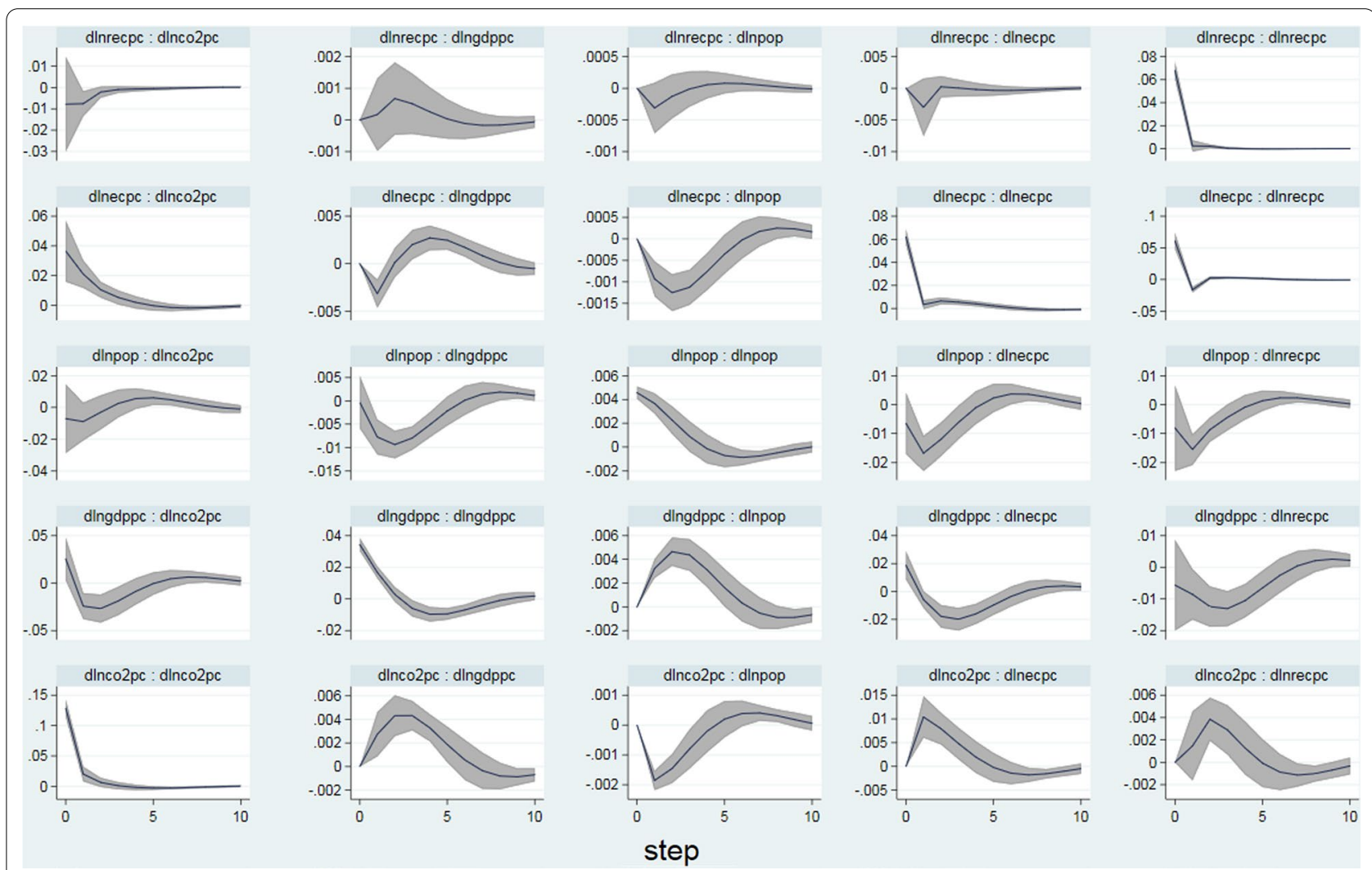

Fig. 3 Orthogonalized impulse response functions. Notes "impulse: response" refers to the impulse and response variable, respectively. A solid middle line depicts the response of one variable to a shock of itself or another endogenous variable. The standard error bands are covered with two shaped lines. The response is statistically significant when the bands do not cross the zero line. The ordering of the variables is $f(d l n p o p, ~ d l n g d p p c$, dlnecpc, dlnrecpc, dlnco2pc)

Based on the panel VAR result, we run the impulse response functions (IRFs) to illustrate the response of one variable to the shock of another variable in the system of the equations while maintaining all other shocks to zeros. The model is assumed to have identical and normally distributed error terms. However, this assumption would be relatively strong. It may be the case that the actual variance-covariance matrix fails to be diagonal in practice. One method to tackle this issue is to decompose the residuals in a way that they become orthogonal. In this paper, the IRFs are based on the Cholesky orthogonal decomposition. However, this method could lead to sensitive results across the order of the variables. The implication is that endogenous variables should be ordered per their degree of exogeneity. Thus, variables that come first in equations are more exogenous than the later ones [39].

In theory, no concrete rule is confirmed on the variable ordering regarding the relationship between $\mathrm{CO}_{2}$ emissions, economic growth, and energy consumption in general and renewable energy in particular. Thus, we note there are multiple sets of variable ordering in contemporary empirical studies. In this paper, we use the following orders. The "population" variable is ordered first, because it appears to be the most exogenous variable. We note a population at the current year affects economic growth, energy and renewable energy consumption, and $\mathrm{CO}_{2}$ emissions. However, the latter variable in the lagged periods impacts the population. The labour force, which serves as an input of production, should be placed in front of economic growth [13]. Second, energy consumption is set to follow economic growth, because current levels of environmental pollution and energy consumption are determined by economic growth [14]. We put renewable energy usage after energy consumption, because an increase in energy demand in the ASEAN region leads to renewable energy usage [3]. Finally, we place $\mathrm{CO}_{2}$ emissions last, because it is the least exogenous variable $[13,14,47] .^{3}$ Consequently, in this paper, we have used

\footnotetext{
${ }^{3}$ As mentioned above, the result of the IRFs is sensitive to the order of the variables. We provide the robustness checks in the latter part of the paper. We would like to thank the reviewer for pointing this out.
} 
the following order of the variables $f($ dlnpop, dlngdppc, dlnecpc, dlnrecpc, dlnco2pc).

Figure 3 illustrates the response of a shock of (the growth of) energy consumption, renewable energy usage, population, economic growth, and $\mathrm{CO}_{2}$ emissions to the shock of itself and other remaining variables. Notably, in the first column, the response of $\mathrm{CO}_{2}$ emissions to a shock in renewable energy growth is negative, but insignificant. The response of $\mathrm{CO}_{2}$ emissions to energy consumption observes an opposite pattern in which it gradually declines and dyes out completely in year 5. Furthermore, $\mathrm{CO}_{2}$ emissions initially have a positive response to a shock in economic growth. The effect then turns negative in year 2 before dying out in year 5 . In the second column, economic growth is found to have a significant responsive pattern to energy consumption, initially decreasing in year 1 and increasing considerably in the next 2 years and then at zero in year 6 . Economic growth responds negatively to a shock of population and positively to $\mathrm{CO}_{2}$ emissions. It does not respond to in renewable energy. The IRFs further support the results for the panel VAR model in Table 5.

The responses of population growth are presented in the third column of Fig. 3. The responsive patterns to a shock of energy consumption, economic growth and $\mathrm{CO}_{2}$ emissions are different. These responses are significant. Population growth responds insignificantly to renewable energy. Next, in the last two columns of Fig. 3, energy consumption and renewable energy appear to respond similarly to population growth, economic growth and $\mathrm{CO}_{2}$ emissions. The responses initially decrease in the first 2 years and then die out after year 5 . In contrast, the response to a shock of $\mathrm{CO}_{2}$ emissions is positive in the first 2 years before it reduces gradually and dies out completely from the 5 th year. Renewable energy consumption responds positively and significantly to energy consumption. However, the reverse pattern cannot be established. The response of renewable energy to a shock of energy consumption declines dramatically from 0.05 to 0 after only a year.

The IRFs results do not consider the magnitude and the degree of the responses of one variable in the remaining endogenous variables. As such, we perform the forecast error variance decomposition to provide more details. From Table 6, a shock in economic activity does significantly cause variations in $\mathrm{CO}_{2}$ emissions. After ten periods, economic activity explains approximately 10 per cent of the variation in $\mathrm{CO}_{2}$ emissions, while the three remaining variables account for a small proportion. Population growth and $\mathrm{CO}_{2}$ emissions contribute approximately 11 per cent and 6 per cent in the variation of economic growth. The variation of economic growth has a significant contribution to population growth,
Table 6 Forecast error variance decomposition

\begin{tabular}{|c|c|c|c|c|c|}
\hline \multirow{2}{*}{$\begin{array}{l}\text { Forecast } \\
\text { horizon }\end{array}$} & \multicolumn{5}{|c|}{ Impulse variable } \\
\hline & dlnco2pc & dlngdppc & dlnpop & dlnrecpc & dlnecpc \\
\hline \multicolumn{6}{|l|}{ dlnco $2 p c$} \\
\hline 1 & 1.000 & 0.000 & 0.000 & 0.000 & 0.000 \\
\hline 2 & 0.944 & 0.040 & 0.003 & 0.011 & 0.001 \\
\hline 6 & 0.883 & 0.094 & 0.006 & 0.014 & 0.002 \\
\hline 10 & 0.877 & 0.099 & 0.008 & 0.014 & 0.002 \\
\hline \multicolumn{6}{|l|}{ dlngdppc } \\
\hline 1 & 0.035 & 0.965 & 0.000 & 0.000 & 0.000 \\
\hline 2 & 0.045 & 0.909 & 0.037 & 0.006 & 0.003 \\
\hline 6 & 0.057 & 0.817 & 0.114 & 0.007 & 0.005 \\
\hline 10 & 0.056 & 0.817 & 0.113 & 0.008 & 0.005 \\
\hline \multicolumn{6}{|l|}{ dlnpop } \\
\hline 1 & 0.003 & 0.000 & 0.997 & 0.000 & 0.000 \\
\hline 2 & 0.051 & 0.257 & 0.685 & 0.000 & 0.007 \\
\hline 6 & 0.032 & 0.601 & 0.346 & 0.009 & 0.012 \\
\hline 10 & 0.034 & 0.597 & 0.347 & 0.009 & 0.012 \\
\hline \multicolumn{6}{|l|}{ dlnrecpc } \\
\hline 1 & 0.016 & 0.007 & 0.007 & 0.970 & 0.000 \\
\hline 2 & 0.017 & 0.014 & 0.034 & 0.915 & 0.020 \\
\hline 6 & 0.017 & 0.066 & 0.041 & 0.857 & 0.019 \\
\hline 10 & 0.017 & 0.067 & 0.043 & 0.854 & 0.019 \\
\hline \multicolumn{6}{|l|}{ dlnecpc } \\
\hline 1 & 0.098 & 0.055 & 0.007 & 0.366 & 0.474 \\
\hline 2 & 0.113 & 0.062 & 0.063 & 0.331 & 0.429 \\
\hline 6 & 0.095 & 0.237 & 0.078 & 0.258 & 0.332 \\
\hline 10 & 0.095 & 0.240 & 0.082 & 0.254 & 0.328 \\
\hline
\end{tabular}

The results are based on orthogonalized impulse responses with ten periods

contributing approximately 60 per cent after ten periods (years). Renewable energy accounts for about 11 per cent of the fluctuation of $\mathrm{CO}_{2}$ emissions and population. Interestingly, when it comes to the variance decomposition of energy consumption, we find that economic growth and renewable energy each explains a proportion of about 25 per cent in the variation of energy consumption. The variance decomposition implies that it is essential for the ASEAN countries to invest more in renewable energy development, promote the wide adoption of renewable energy on a broader scale, and accelerate renewable energy in the energy mix.

The results of a traditional Granger causality test among $\mathrm{CO}_{2}$ emissions, renewable energy consumption, population, energy consumption, and economic growth are shown in Table 7. The bidirectional Granger causality in each pair among economic growth, energy consumption and $\mathrm{CO}_{2}$ emissions are found. Furthermore, Table 7 indicates a bidirectional Granger causality between population growth and economic growth. We 
Table 7 Result of Granger causality tests

\begin{tabular}{|c|c|c|c|c|}
\hline \multirow[t]{2}{*}{ Null hypothesis } & \multicolumn{2}{|l|}{ Traditional test } & \multicolumn{2}{|l|}{ D-H test } \\
\hline & Chi2-statistic & Prob & $Z$ bar-statistic & Prob \\
\hline dlngdppc does not Granger-cause dlnco2pc & 28.88 & 0.00 & 0.78 & 0.43 \\
\hline dlnpop does not Granger-cause dlnco2pc & 1.97 & 0.16 & 9.14 & 0.00 \\
\hline dlnrecpc does not Granger-cause dlnco2pc & 7.27 & 0.01 & -0.54 & 0.59 \\
\hline dlnecpc does not Granger-cause dlnco2pc & 18.70 & 0.00 & 0.24 & 0.81 \\
\hline dlnco2pc does not Granger-cause dlngdppc & 8.41 & 0.00 & 2.11 & 0.04 \\
\hline dlnpop does not Granger-cause dlngdppc & 44.49 & 0.00 & 2.01 & 0.05 \\
\hline dlnrecpc does not Granger-cause dlngdppc & 0.34 & 0.56 & 2.48 & 0.01 \\
\hline dlnecpc does not Granger-cause dlngdppc & 13.60 & 0.00 & 2.40 & 0.02 \\
\hline dlnco2pc does not Granger-cause dlnpop & 228.17 & 0.00 & 6.42 & 0.00 \\
\hline dlngdppc does not Granger-cause dlnpop & 88.80 & 0.00 & 7.12 & 0.00 \\
\hline dlnrecpc does not Granger-cause dlnpop & 11.59 & 0.00 & 5.94 & 0.00 \\
\hline dlnecpc does not Granger-cause dlnpop & 0.02 & 0.90 & 8.36 & 0.00 \\
\hline dlnco2pc does not Granger-cause dlnrecpc & 0.90 & 0.34 & 0.99 & 0.32 \\
\hline dlngdppc does not Granger-cause dlnrecpc & 0.55 & 0.46 & -1.27 & 0.20 \\
\hline dlnpop does not Granger-cause dlnrecpc & 63.77 & 0.00 & 7.86 & 0.00 \\
\hline dlnecpc does not Granger-cause dlnrecpc & 31.02 & 0.00 & -0.86 & 0.38 \\
\hline dlnco2pc does not Granger-cause dlnecpc & 23.44 & 0.00 & 0.46 & 0.65 \\
\hline dlngdppc does not Granger-cause dlnecpc & 7.59 & 0.01 & 1.14 & 0.25 \\
\hline dlnpop does not Granger-cause dlnecpc & 37.32 & 0.00 & -0.19 & 0.85 \\
\hline dlnrecpc does not Granger-cause dlnecpc & 1.28 & 0.26 & -0.99 & 0.32 \\
\hline
\end{tabular}

The traditional Granger causality test is based on the panel VAR model within the GMM framework

$\mathrm{D}-\mathrm{H}$ test is based on the heterogeneous-panel Granger non-causality test

also find a unidirectional Granger causality running from population growth to energy consumption and renewable energy. These findings further confirm the impact of population growth on economic activity and renewable energy usage. We find that renewable energy usage unidirectionally causes $\mathrm{CO}_{2}$ emissions. A unidirectional causality from energy consumption to renewable energy is found. Therefore, the results do not support the causality relationship between renewable energy and economic growth in the ASEAN region, which is in line with previous studies [46].

It should be noted that the traditional panel-based causality test assumes a homogeneity of slope coefficients on estimated parameters when a joint causality restriction is imposed. However, this assumption would be relatively strong [48]. In addition, assuming slope parameters to be homogenous does not capture country-specific characteristics, raising a concern of heterogeneity. The panel-based Granger non-causality test by Dumitrescu and Hurlin [49] allows taking heterogeneity into consideration. Furthermore, the test simplifies the standardized, average Wald statistics. The results from these tests are efficient. The test also has a good small sample property through Monte Carlo experiments. As such, the outcome is efficient, even in the case of limited $\mathrm{T}$ and $\mathrm{N}$ dimensions.
However, a minor drawback is that when the null hypothesis is rejected, the test does not provide a number of the cross units in the panel which are rejected. This study uses the Dumitrescu and Hurlin Granger non-causality test for heterogeneous panels to examine the causality direction among carbon emissions, energy consumption, renewable energy consumption, economic growth, and population growth as a robustness check. The Dumitrescu and Hurlin panel-based Granger non-causality test results are reported in the last two columns of Table 7.

\section{Discussions}

Our first finding supports the feedback hypothesis between energy consumption, economic growth, and $\mathrm{CO}_{2}$ emissions, because any pair of these three variables causes bidirectionally each other. Apart from contributing to the extensive literature on the energy-growthenvironment relationship, our findings are different from preceding works for the ASEAN region using panel data analysis. Specifically, some studies only confirm the impact of energy consumption and economic growth on $\mathrm{CO}_{2}$ emissions $[17,18]$. Other studies confirm bidirectional causality between economic growth and energy consumption (the feedback hypothesis) and unidirectional causality from economic growth to $\mathrm{CO}_{2}$ emissions 
(the conservation hypothesis) [1]. A possible explanation for the difference in findings is that previous studies use a panel of the ASEAN-5 and focus on the long-run effect. Our paper has a larger sample of the ASEAN-7 countries, and we focus on the short-run effect. Furthermore, it is documented that the energy-growth-environment causality varies in both short-run and long-run horizons and the countries in the sample [20]. The interactive link suggests that certain policies targeting short-run economic growth should take environment degradation and energy security into consideration to pursue sustainable economic growth and development.

Another significant contribution of our study to the existing literature is linked with the consideration of renewable energy. First, we find that energy consumption Granger causes renewable energy consumption unidirectionally. The finding supports the view that the ASEAN countries depend heavily on fossil fuel energy. Increasing renewable energy usage is a potential solution to address the energy issue [3]. Second, we find a unidirectional causality running from population to renewable energy and from renewable energy to $\mathrm{CO}_{2}$ emissions. These findings offer the following implications. The ASEAN region could take advantage of its population size to increase renewable energy supply and shift energy consumption from fossil fuels to a cleaner renewable energy source at the household level. The public programs aim to raise awareness, and the adoption of renewable energy among households would stabilize the energy supply and demand and reduce environmental degradation. It should be noted that policies, including agreements and regulations for renewable energy development, are highly fragmented between each member of the ASEAN region [2]. Therefore, the exchange of ideas and the increased cooperation between the ASEAN members in a formal arrangement should be encouraged and promoted. Finally, we document the importance of population growth in examining the energy-growth-environment nexus as predicted by the STIRPAT model and previous empirical studies [6, 30-32].

Although the current study addresses the causality relationship among the surveyed variables, there are limitations. First, the potential effect of economic structure changes regarding trade openness and financial development is of importance. This is especially relevant for ASEAN economies over the last decades, because the region's economic growth is highly associated with increased trade openness and financial exposure. This limitation is addressed to some extent in our robustness check below by considering financial development. Second, the paper focuses on the short run rather than the long run, which could underestimate the importance of renewable energy usage on economic growth, energy consumption and energy security. Thus, a more careful analysis must consider both short- and long-run effects.

We conduct two robustness checks to ensure the validity of our empirical results. We reverse the variable ordering for the first robustness check so that the variable order is as $f(\mathrm{dln} r e c$, dlnec, dlnpop, dlngdppc, dlnco2pc). This order of variables is similar to previous empirical studies, which consider that renewable energy affects economic growth $[13,15,47]$. On this basis, we put energy and renewable energy consumption before economic growth. This choice is appropriate for our empirical case for the ASEAN region, because we find a unidirectional causality from renewable energy to economic growth in the DH Granger test. In addition, we put renewable energy before energy consumption to check whether the order of these two variables matters in the IRFs analysis. This order also allows us to consider the effect of renewable energy usage on other variables with time delays without reverse effects. The orthogonalized IRFs are portrayed in Fig. 4. Notably, the responses of renewable energy usage to other variables change significantly across the two sets of order, as illustrated in the last column of Figs. 3 and 4. Specifically, Fig. 3 shows a positive response of renewable energy to energy consumption, while Fig. 4 reveals a negative pattern. These two figures show that the responsive pattern of renewable energy to economic growth and population growth are significantly different in relation to the number of periods in which the responses dye out. Third, renewable energy responds to energy consumption in the same way, as presented in both figures. Thus, the changes could result from the relative order of renewable energy compared to the remaining variables. These findings highlight that the order of variables matters in the IRFs analysis.

For the second robustness check, we account for the effect of economic structural changes as ASEAN economies have recorded high economic growth from trade and financial exposure. However, the trade data for Myanmar is not available. Therefore, there is a trade-off between the inclusion of trade openness and the exclusion of Myanmar from the sample. As such, we add financial development rather than trade openness. We utilize a new broad-based index of financial development, which is constructed by Svirydzenka [50]. This index is available from the International Monetary Fund (IMF) database. The relationship between financial development and $\mathrm{CO}_{2}$ emission is well-established [51-53]. The orthogonalized IRFs with the inclusion of financial development are presented in Fig. 5. ${ }^{4}$ We keep the same variable ordering from the first robustness check and add financial development into the regression as the

\footnotetext{
${ }^{4}$ We re-do the entire analysis process in which financial inclusion is added to the model. The results are not presented but are available upon request. We thank the reviewer for this constructive suggestion.
} 


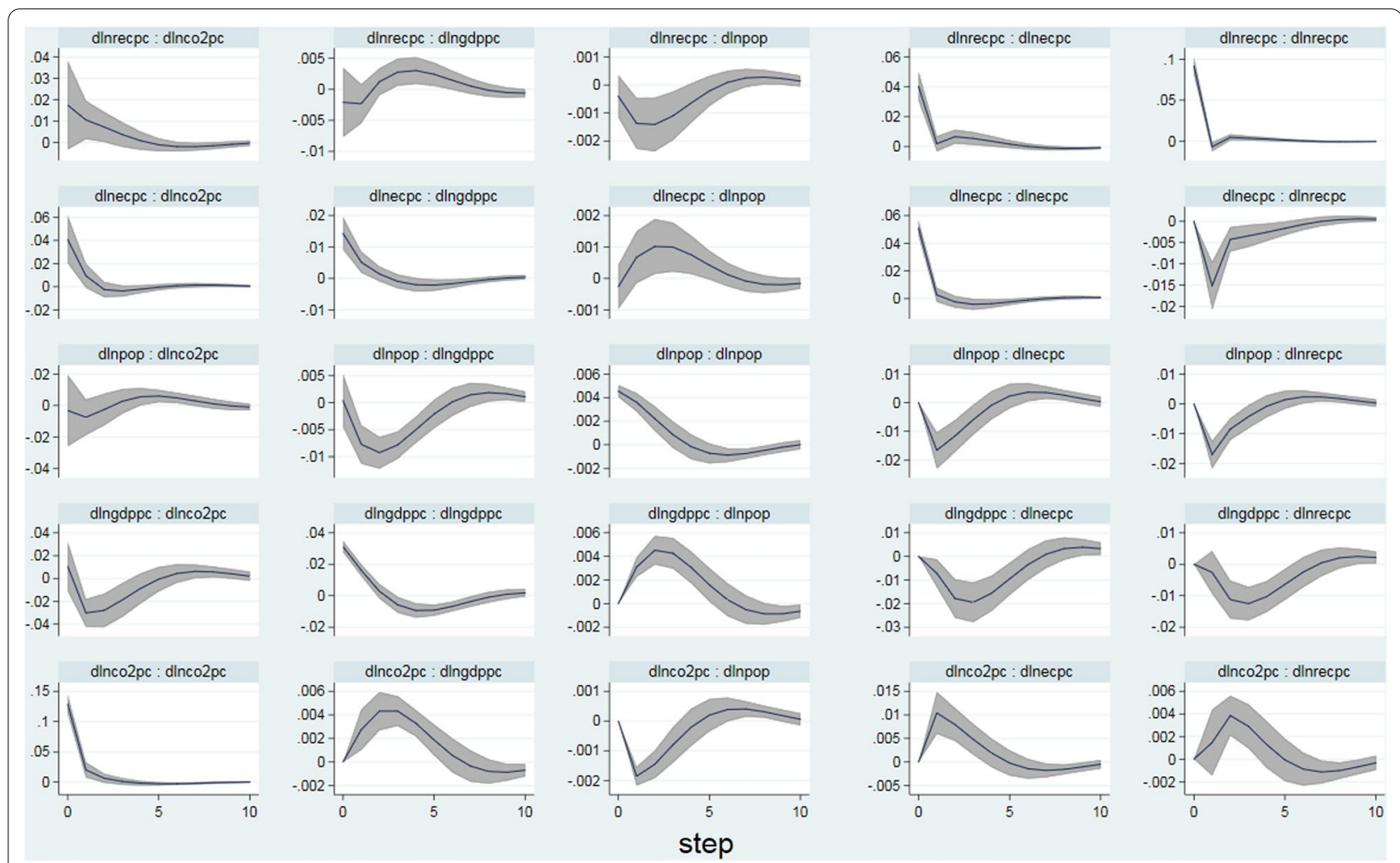

Fig. 4 Orthogonalized impulse response functions with the change in the variable ordering. Note Regarding the significance, refer to the note in Fig. 3. The variable order is $f(d \ln r e c p c$, dlnecpc, dlnpop, dlngdppc, dlnco2pc)

first variable. This setting is similar to the work [15], which considers that financial development impacts energy consumption and economic growth. In the last column of Fig. 5, financial development is statistically responsive to all the variables used in our analysis, except for $\mathrm{CO}_{2}$ emissions. It is found that financial development responds positively to innovations in economic growth, and it reacts adversely to shocks in population growth, renewable energy usage and energy consumption. This finding supplements the contemporary literature concerning financial development and economic growth, energy consumption in general and renewable energy consumption in particular $[15,21,51$, 53]. The response of financial development to population growth follows the perspective of economic historians, who point out the critical role placed by banks on urban development. Our finding is not in line with the work [54], which documents a significant and positive link between financial development and subsequent population growth. Furthermore, a shock in financial development affects economic growth rather than other remaining variables. This finding highlights the link between economic growth and financial development. However, we cannot confirm the impact of financial development on energy consumption, renewable energy consumption, $\mathrm{CO}_{2}$ emissions and population growth in the ASEAN economies. Our findings are not in line with a study that stresses the long-run effect of financial development on environmental degradation for five ASEAN countries [53]. The inconsistent finding could be that we focus on the short-run analysis as compared to the long-run analysis. Finally, the inclusion of financial development into the original system does not affect the responsive pattern of the IRFs, since the last five rows of Fig. 5 are almost identical to those of Fig. 4. The only difference is that the response of $\mathrm{CO}_{2}$ emissions to shocks in population growth become statistically significant in Fig. 5.

Another concern is associated with the Granger causality inference. The change in variable ordering does not affect the findings regarding the Granger causality, because these tests are based on the Wald statistics from the same panel VAR model. However, when financial development is added to the system of endogenous variables, we find a bidirectional causality between $\mathrm{CO}_{2}$ emissions and population growth and a unidirectional causality running from renewable energy to economic growth. Compared to the causality results in Table 5, there is a unidirectional causality running from $\mathrm{CO}_{2}$ emissions to population growth. Furthermore, we observe a unidirectional causality running from energy 


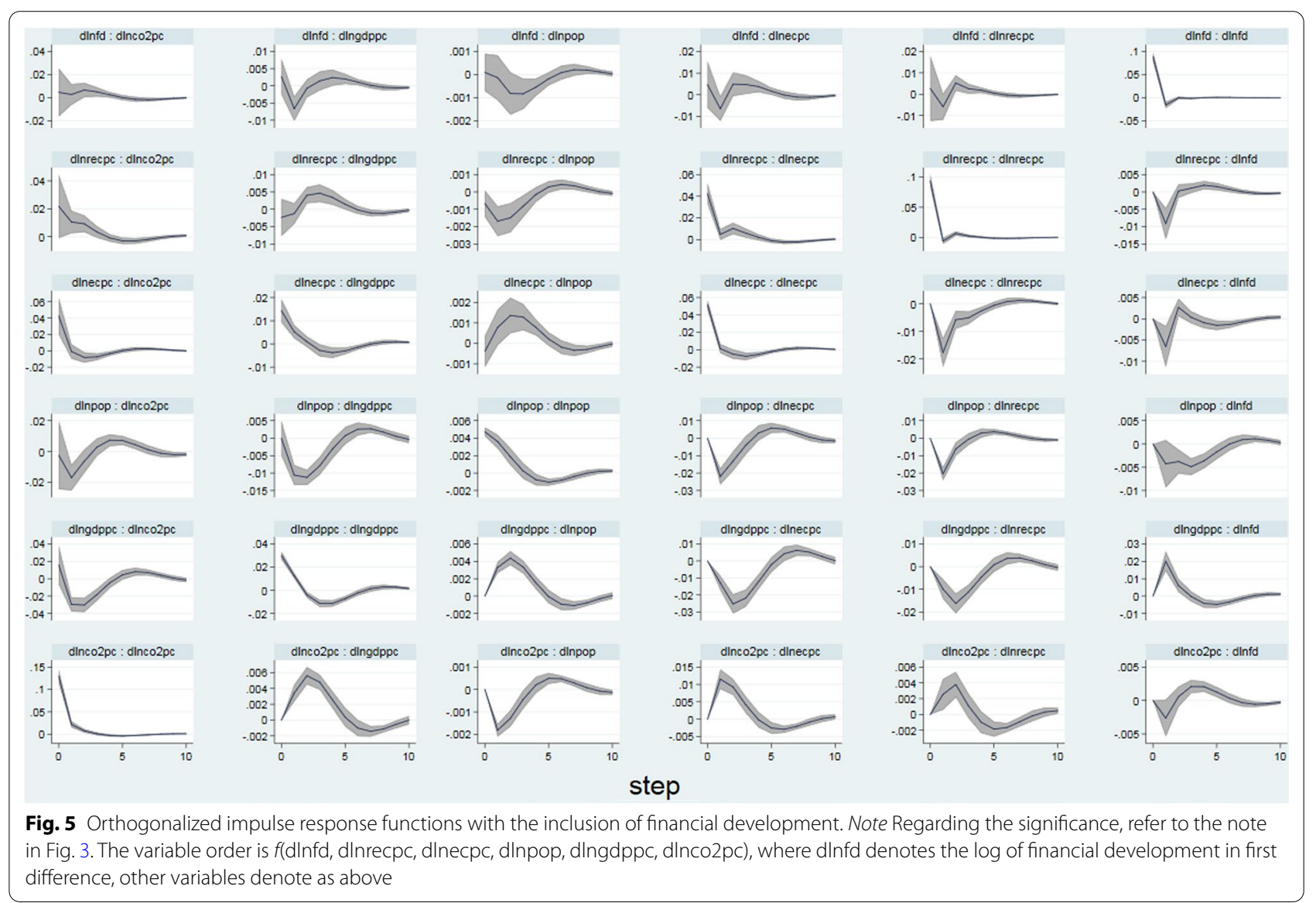

consumption to population growth in Table 5. An explanation for the difference in relation to the causal relationship would be the impact of financial development on other endogenous variables in the panel VAR system.

\section{Conclusions and policy implications}

This study investigates the relationship between $\mathrm{CO}_{2}$ emissions, economic growth, energy consumption, population growth and renewable energy usage for the ASEAN nations. A panel of seven ASEAN countries and the panel VAR framework are used in this paper. The main findings from the paper are summarized as follows. First, our results confirm that energy consumption is positively associated with $\mathrm{CO}_{2}$ emissions and vice versa and that there is a negative marginal effect of renewable energy usage on $\mathrm{CO}_{2}$ emission. Second, after ten periods (years), renewable energy usage and economic growth explain a substantial proportion of energy consumption variation. Third, we find bidirectional Granger causality between $\mathrm{CO}_{2}$ emissions, economic growth, and energy consumption. A unidirectional Granger causality, either running from population growth to renewable energy or running from renewable energy usage to $\mathrm{CO}_{2}$ emissions, is found. Important policy implications for the ASEAN region have emerged on the ground of these findings.

The ASEAN region has its own characteristics. As such, an investigation of the relationship between economic growth, $\mathrm{CO}_{2}$ emissions and energy consumption for this region should be conducted. The ASEAN region has been acknowledged as one of the most dynamic economic regions globally. Members of the region have achieved impressive high economic growth in the last three decades. Countries in the ASEAN region have also made transforming progress towards regional economic integration. Our results indicate that energy consumption appears to be an indispensable element in boosting and maintaining economic growth and increasing carbon emissions, leading to environmental degradation. To a more considerable extent, at the regional ASEAN level, a strong relationship between economic growth, $\mathrm{CO}_{2}$ emissions and energy consumption is observed empirically. We consider that economic plans or strategies that enhance economic growth will exhibit a trade-off between increased energy consumption and higher carbon emissions leading to a deterioration of environmental quality. Therefore, it is suggested that the cooperation 
of ASEAN members is vital to the achievement of sustainable development goals.

Our findings confirm the potential role of using renewable energy on economic activity and environmental degradation with the population as a key element. Our study's focus is on the ASEAN-7. The extended STIRPAT model provides additional empirical evidence on the energy-environment-growth nexus to the existing literature [1, 28-34, 55]. In addition to financial development, control variables, such as foreign direct investment, trade openness, and urbanization that can affect the adoption of renewable energy should be considered. These variables are demonstrated to play a decisive role in previous studies $[1,7,13,15,56]$. Renewable energy should be considered a supplement source of energy for an increasingly higher demand for energy consumption. More importantly, this energy source can contribute to economic growth in the region towards sustainable economic growth and development $[28,46,57,58]$. As such, recent targets and commitments among the ASEAN countries concerning the use of renewable energy in their energy structure appear to be on the right track. In addition, efforts to increase the share of renewable energy in the total primary energy supply should be encouraged.

\begin{abstract}
Abbreviations
ACE: ASEAN Economic Community; ARDL: Autoregressive distributed lagged; ASEAN: Association of Southeast Asian Nations; ASEAN-5: 5 ASEAN countries (Indonesia, Malaysia, the Philippines, Singapore and Thailand); ASEAN-7: 7 ASEAN countries (ASEAN-5 plus Myanmar and Vietnam); $\mathrm{CO}_{2}$ : Carbon dioxide; D-H: Dumitrescu and Hurlin; IRFs: Impulse response functions; GDP: Gross domestic product; GMM: Generalized method of moments; STIRPAT: Stochastic impacts by regression on population, affluence, and technology; VAR: Vector autoregressive.
\end{abstract}

\section{Acknowledgements}

We would like to express our sincere thanks to the editors and three anonymous referees, whose comments are greatly constructive and helpful. The final manuscript has greatly benefitted from these excellent comments. We would also like to thank a language editing service from AMV Consulting and Advisory Services for proofreading the final version of the paper. Finally, we are also thankful to Vietnam's Ministry of Education and Training and Ho Chi Minh City Open University.

\section{Authors' contributions}

All authors have made substantial contributions to the conception, design of the work; analysis; and drafting of the paper. All authors read and approved the final manuscript.

\section{Funding}

This research is funded by Vietnam's Ministry of Education and Training (B2020-MBS-03).

\section{Availability of supporting data}

The data sets used in this study are available from the corresponding author upon request.

\section{Declarations}

Ethics approval and consent to participate Not applicable.

\section{Consent for publication}

The article is original, has not already been published in a journal, and is not currently under consideration by another journal.

\section{Competing interests}

The authors declare that they have no competing interests.

Received: 3 January 2021 Accepted: 16 August 2021

Published online: 30 August 2021

\section{References}

1. Munir Q, Lean $\mathrm{HH}$, Smyth R (2020) $\mathrm{CO}_{2}$ emissions, energy consumption and economic growth in the ASEAN-5 countries: a cross-sectional dependence approach. Energy Econ. https://doi.org/10.1016/j.eneco. 2019.104571

2. Erdiwansyah M, Mamat R et al (2019) Target and demand for renewable energy across 10 ASEAN countries by 2040. Electr J 32:106670. https:// doi.org/10.1016/j.tej.2019.106670

3. ACE (2017) The 5th ASEAN energy outlook 2015-2040 (AEO5). ACE, Jakarta

4. Can Şener ŞE, Sharp JL, Anctil A (2018) Factors impacting diverging paths of renewable energy: a review. Renew Sustain Energy Rev 81:2335-2342. https://doi.org/10.1016/j.rser.2017.06.042

5. Vo DH, Vo AT, Ho CM, Nguyen HM (2020) The role of renewable energy, alternative and nuclear energy in mitigating carbon emissions in the CPTPP countries. Renew Energy. https://doi.org/10.1016/j.renene.2020.07. 093

6. Dong $\mathrm{K}$, Hochman $\mathrm{G}$, Zhang $\mathrm{Y}$ et al (2018) $\mathrm{CO}_{2}$ emissions, economic and population growth, and renewable energy: empirical evidence across regions. Energy Econ 75:180-192. https://doi.org/10.1016/j.eneco.2018. 08.017

7. Nathaniel S, Khan SAR (2020) The nexus between urbanization, renewable energy, trade, and ecological footprint in ASEAN countries. J Clean Prod 272:122709. https://doi.org/10.1016/j.jclepro.2020.122709

8. Rahman MM, Velayutham E (2020) Renewable and non-renewable energy consumption-economic growth nexus: new evidence from South Asia. Renew Energy 147:399-408. https://doi.org/10.1016/j.renene.2019. 09.007

9. Liu X, Zhang S, Bae J (2017) The impact of renewable energy and agriculture on carbon dioxide emissions: investigating the environmental Kuznets curve in four selected ASEAN countries. J Clean Prod 164:12391247. https://doi.org/10.1016/j.jclepro.2017.07.086

10. Abrigo MRM, Love I (2016) Estimation of panel vector autoregression in Stata. Stata J 16:778-804. https://doi.org/10.1177/1536867×1601600314

11. Murphy RH, O'Reilly C (2019) Applying panel vector autoregression to institutions, human capital, and output. Empir Econ 57:1633-1652. https://doi.org/10.1007/s00181-018-1562-0

12. Vo DH, Van NP, Nguyen HM et al (2019) Derivatives market and economic growth nexus: policy implications for emerging markets. N Am J Econ Financ. https://doi.org/10.1016/j.najef.2018.10.014

13. Charfeddine L, Kahia M (2019) Impact of renewable energy consumption and financial development on $\mathrm{CO}_{2}$ emissions and economic growth in the MENA region: a panel vector autoregressive (PVAR) analysis. Renew Energy 139:198-213. https://doi.org/10.1016/j.renene.2019.01.010

14. Acheampong $\mathrm{AO}$ (2018) Economic growth, $\mathrm{CO}_{2}$ emissions and energy consumption: what causes what and where? Energy Econ 74:677-692. https://doi.org/10.1016/..eneco.2018.07.022

15. Ouyang Y, Li P (2018) On the nexus of financial development, economic growth, and energy consumption in China: new perspective from a GMM panel VAR approach. Energy Econ 71:238-252. https://doi.org/10.1016/j. eneco.2018.02.015

16. Tzeremes $P$ (2018) Time-varying causality between energy consumption, $\mathrm{CO}_{2}$ emissions, and economic growth: evidence from US states. Environ Sci Pollut Res 25:6044-6060. https://doi.org/10.1007/s11356-017-0979-x

17. Zhu H, Duana L, Guoa Y, Yu K (2016) The effects of FDI, economic growth and energy consumption on carbon emissions in ASEAN-5: evidence from panel quantile regression. Econ Model 58:237-248 
18. Heidari $\mathrm{H}$, Turan Katircioğlu S, Saeidpour L (2015) Economic growth, $\mathrm{CO}_{2}$ emissions, and energy consumption in the five ASEAN countries. Int J Electr Power Energy Syst 64:785-791. https://doi.org/10.1016/j.jepes.2014.07.081

19. Hwang J-H, Yoo S-H (2014) Energy consumption, $\mathrm{CO}_{2}$ emissions, and economic growth: evidence from Indonesia. Qual Quant 48:63-73

20. Saboori B, Sulaiman J (2013) $\mathrm{CO}_{2}$ emissions, energy consumption and economic growth in the association of Southeast Asian Nations (ASEAN) countries: a cointegration approach. Energy 55:813-822. https://doi.org/10. 1016/j.energy.2013.04.038

21. Shahzad SJH, Kumar RR, Zakaria M, Hurr M (2017) Carbon emission, energy consumption, trade openness and financial development in Pakistan: a revisit. Renew Sustain Energy Rev 70:185-192. https://doi.org/10.1016/j.rser. 2016.11.042

22. Tong T, Ortiz J, Xu C, Li F (2020) Economic growth, energy consumption, and carbon dioxide emissions in the E7 countries: a bootstrap ARDL bound test. Energy Sustain Soc 10:1-17. https://doi.org/10.1186/s13705-020-00253-6

23. Al-Mulali U, Saboori B, Ozturk I (2015) Investigating the environmental Kuznets curve hypothesis in Vietnam. Energy Policy 76:123-131. https://doi. org/10.1016/j.enpol.2014.11.019

24. Raza SA, Shah N (2018) Testing environmental Kuznets curve hypothesis in G7 countries: the role of renewable energy consumption and trade. Environ Sci Pollut Res 25:26965-26977. https://doi.org/10.1007/s11356-018-2673-Z

25. Nguyen KH, Kakinaka M (2019) Renewable energy consumption, carbon emissions, and development stages: some evidence from panel cointegration analysis. Renew Energy 132:1049-1057. https://doi.org/10.1016/j. renene.2018.08.069

26. Solarin SA, Al-Mulali U, Ozturk I (2017) Validating the environmental Kuznets curve hypothesis in India and China: the role of hydroelectricity consumption. Renew Sustain Energy Rev 80:1578-1587. https://doi.org/10.1016/j.rser. 2017.07.028

27. Amoah A, Kwablah E, Korle K, Offei D (2020) Renewable energy consumption in Africa: the role of economic well-being and economic freedom. Energy Sustain Soc 10:1-17. https://doi.org/10.1186/s13705-020-00264-3

28. Nepal R, Paija N (2019) A multivariate time series analysis of energy consumption, real output and pollutant emissions in a developing economy: new evidence from Nepal. Econ Model 77:164-173. https://doi.org/10. 1016/j.econmod.2018.05.023

29. Nepal R, Paija N (2019) Energy security, electricity, population and economic growth: the case of a developing South Asian resource-rich economy. Energy Policy 132:771-781. https://doi.org/10.1016/j.enpol.2019.05.054

30. Begum RA, Sohag K, Abdullah SMS, Jaafar M (2015) $\mathrm{CO}_{2}$ emissions, energy consumption, economic and population growth in Malaysia. Renew Sustain Energy Rev 41:594-601. https://doi.org/10.1016/j.rser.2014.07.205

31. Lohwasser J, Schaffer A, Brieden A (2020) The role of demographic and economic drivers on the environment in traditional and standardized STIRPAT analysis. Ecol Econ 178:106811. https://doi.org/10.1016/j.ecolecon.2020. 106811

32. Ghazali A, Ali G (2019) Investigation of key contributors of $\mathrm{CO}_{2}$ emissions in extended STIRPAT model for newly industrialized countries: a dynamic common correlated estimator (DCCE) approach. Energy Rep 5:242-252. https:// doi.org/10.1016/j.egyr.2019.02.006

33. Dietz T, Rosa EA (1997) Effects of population and affluence on $\mathrm{CO}_{2}$ emissions. Proc Natl Acad Sci USA 94:175-179. https://doi.org/10.1073/pnas.94.1. 175

34. Dong K, Hochman G, Zhang Y et al (2018) $\mathrm{CO}_{2}$ emissions, economic and population growth, and renewable energy: empirical evidence across regions. Energy Econ 75:180-192. https://doi.org/10.1016/j.eneco.2018.08. 017

35. Tiba S, Omri A (2017) Literature survey on the relationships between energy, environment and economic growth. Renew Sustain Energy Rev 69:11291146. https://doi.org/10.1016/j.rser.2016.09.113

36. Sadorsky P (2009) Renewable energy consumption, $\mathrm{CO}_{2}$ emissions and oil prices in the G7 countries. Energy Econ 31:456-462. https://doi.org/10. 1016/j.eneco.2008.12.010

37. Edenhofer $\mathrm{O}$, Hirth L, Knopf B et al (2013) On the economics of renewable energy. Energy Econ 40:S12-S23. https://doi.org/10.1016/j.eneco.2013.09. 015

38. Salim RA, Rafiq S (2012) Why do some emerging economies proactively accelerate the adoption of renewable energy? Energy Econ 34:1051-1057. https://doi.org/10.1016/j.eneco.2011.08.015
39. Love I, Zicchino L (2006) Financial development and dynamic investment behaviour: evidence from panel VAR. Q Rev Econ Financ 46:190-210. https://doi.org/10.1016/j.qref.2005.11.007

40. Arellano M, Bond S (1991) Some tests of specification for panel data: Monte Carlo evidence and an application to employment equations. Rev Econ Stud 58:277-297. https://doi.org/10.2307/2297968

41. Choi I (2001) Unit root tests for panel data. J Int Money Financ 20:249-272. https://doi.org/10.1016/S0261-5606(00)00048-6

42. Dickey DA, Fuller WA (1979) Distribution of the estimators for autoregressive time series with a unit root. J Am Stat Assoc 74:427-431

43. Pedroni $P$ (1999) Critical values for cointegration tests in heterogeneous panels with multiple regressors. Oxf Bull Econ Stat 61:653-670. https://doi. org/10.1111/1468-0084.61.s1.14

44. Pedroni $P$ (2001) Purchasing power parity tests in cointegrated panels. Rev Econ Stat 83:727-731

45. Westerlund $J$ (2007) Testing for error correction in panel data. Oxf Bull Econ Stat 69:709-748. https://doi.org/10.1111/j.1468-0084.2007.00477.x

46. Bekhet HA, Othman NS (2018) The role of renewable energy to validate dynamic interaction between $\mathrm{CO}_{2}$ emissions and GDP towards sustainable development in Malaysia. Energy Econ. https://doi.org/10.1016/j.eneco. 2018.03.028

47. Tiwari AK (2011) A structural VAR analysis of renewable energy consumption, real GDP and $\mathrm{CO}_{2}$ emissions: evidence from India. Econ Bull 31:1793-1806

48. Granger CWJ (2003) Some aspects of causal relationships. J Econ 112:69-71. https://doi.org/10.1016/S0304-4076(02)00148-3

49. Dumitrescu El, Hurlin C (2012) Testing for Granger non-causality in heterogeneous panels. Econ Model 29:1450-1460. https://doi.org/10.1016/j. econmod.2012.02.014

50. Svirydzenka K (2016) Introducing a new broad-based index of financial development. IMF Work Pap 16:1. https://doi.org/10.5089/9781513583709. 001

51. Omri A, Daly S, Rault C, Chaibi A (2015) Financial development, environmental quality, trade and economic growth: what causes what in MENA countries. Energy Econ 48:242-252. https://doi.org/10.1016/j.eneco.2015.01. 008

52. Ertugrul HM, Cetin M, Seker F, Dogan E (2016) The impact of trade openness on global carbon dioxide emissions: evidence from the top ten emitters among developing countries. Ecol Indic 67:543-555. https://doi.org/10. 1016/j.ecolind.2016.03.027

53. Nasir MA, Duc Huynh TL, Xuan Tram HT (2019) Role of financial development, economic growth \& foreign direct investment in driving climate change: a case of emerging ASEAN. J Environ Manag 242:131-141. https:// doi.org/10.1016/j.jenvman.2019.03.112

54. Bodenhorn $\mathrm{H}$, Cuberes D. Financial development and city growth: evidence from northeastern American cities, 1790-1870. 2010.

55. To AH, Ha DTT, Nguyen HM, Vo DH (2019) The impact of foreign direct investment on environment degradation: evidence from emerging markets in Asia. Int J Environ Res Public Health. https://doi.org/10.3390/ijerph1609 1636

56. Shahbaz M, Haouas I, Van HTH (2019) Economic growth and environmental degradation in Vietnam: is the environmental Kuznets curve a complete picture? Emerg Mark Rev 38:197-218. https://doi.org/10.1016/j.ememar.2018. 12.006

57. Kyophilavong P, Shahbaz M, Anwar S, Masood S (2015) The energy-growth nexus in Thailand: does trade openness boost energy consumption? Renew Sustain Energy Rev 46:265-274. https://doi.org/10.1016/j.rser.2015.02.004

58. Omri A (2013) $\mathrm{CO}_{2}$ emissions, energy consumption and economic growth nexus in MENA countries: evidence from simultaneous equations models. Energy Econ 40:657-664. https://doi.org/10.1016/j.eneco.2013.09.003

\section{Publisher's Note}

Springer Nature remains neutral with regard to jurisdictional claims in published maps and institutional affiliations. 